\title{
PENGEMBANGAN MODUL GEOGRAFI BERBASIS POE (PREDICT, OBSERVE, EXPLAIN) PADA MATERI PEMANFAATAN PETA, PENGINDERAAN JAUH, DAN SIG DI KELAS XII SMA NEGERI 1 BUKITTINGGI
}

\author{
Fadhilah Santi Harahap ${ }^{1}$, Yurni Suasti ${ }^{2}$ \\ 1, 2, ${ }^{3}$ Program Studi Pendidikan Geografi - Jurusan Geografi \\ Fakultas Ilmu Sosial, Universitas Negeri Padang \\ e-mail: fadhilahsanti13@gmail.com
}

\begin{abstract}
Abstrak
Penelitian ini bertujuan untuk mengembangkan, mengetahui dan mendeskripsikan kevalidan dan kepraktisan modul geografi berbasis POE (Predict, Observe, Explain) pada materi pemanfaatan peta, penginderaan jauh, dan SIG kelas XII SMA Negeri 1 Bukittinggi. Jenis penelitian ini adalah penelitian dan pengembangan $(R \& D)$ pengembangan dengan mengadaptasi model 4-D. Modul dikembangkan dalam empat tahapan yaitu (1) pendefinisian (define), (2) perancangan (design), (3) pengembangan (develop), (4) penyebaran (disseminate). Validasi dilakukan dua orang dosen geografi. Kepraktisan dilakukan oleh 3 orang guru dan 35 orang siswa SMA Negeri 1 Bukittinggi. Hasil penelitian menunjukkan bahwa modul geografi berbasis POE pada materi pemanfaatan peta, penginderaanjauh, dan SIG ini valid dan praktis untuk digunakan dalam pembelajaran. Terbukti dari nilai akhir oleh dua orang dosen yaitu 0,70 dengan kategori valid. Nilai akhir dari guru yaitu 4,21 dan nilai akhir dari siswa yaitu 4,36 dengan kategori praktis.
\end{abstract}

Kata Kunci: Modul, 4-D, Predict, Observe, Explain

\begin{abstract}
This research aims to develop, know and describe the validity and practicality of POE (Predict, Observe, Explain) geography module on map utilization material, remote sensing and GIS class XII SMA Negeri 1 Bukittinggi. This type of research is research and development (R\&D) by adapting 4-D model. Modules are developed in four stages: (1) define, (2) design, (3) development, (4) disseminate. Validation was done by two lecturers of geography. Practicality is done by 3 teachers and 35 students of SMA Negeri 1 Bukittinggi. The results show that POE-based geographic module on map utilization, remote sensing and GIS material is valid and practical for use in learning. Evident from the final value by two lecturers is 0,70 with valid category. The final value of teachers is 4,21 and the final score of the students is 4,36 with valid category.
\end{abstract}

Keywords: Module, 4-D, Predict, Observe, Explain

\footnotetext{
${ }^{1}$ Mahasiswa Program Studi Pendidikan Geografi untuk Wisuda Maret 2018

${ }^{2}$ Dosen Jurusan Geografi Fakultas Ilmu Sosial Universitas Negeri Padang, Pembimbing 1: Dra. Yurni Suasti M.Si, Pembimbing 2: Nofrion, S.Pd, M.Pd
} 


\section{PENDAHULUAN}

Belajar merupakan suatu proses perubahan dalam mendapatkan pengetahuan dan pelajaran dari yang awalnya tidak tahu menjadi tahu. Di dalam proses belajar seseorang akan mengalami perubahan kearah yang lebih baik sesuai pengalaman dan pengetahuan yang didapatkan.

Pembelajaran merupakan suatu kegiatan dalam rangka melaksanakan kurikulum pada suatu lembaga pendidikan untuk membantu siswa mencapai tujuan pendidikan yang telah ditetapkan. Menurut Walter Dick; Suasti (2003) pembelajaran adalah proses interaksi peserta didik dengan pendidik dan belajar pada suatu lingkungan belajar.

Tercapainya tujuan pembelajaran harus didasari oleh adanya aktivitas belajar yang efektif. Namun, hasil riset Nofrion (2018:2) mengungkapkan "Learning activities in learning is still in the corridor of basic activities (listening, Asking and responding), artinya, bahwa aktivitas belajar yang sering terjadi dalam pembelajaran Geografi masih berada pada tingkat dasar. Temuan lain dalam pembelajaran Geografi adalah masih rendahnya kualitas soal dan permasalahan yang disajikan guru dalam pembelajaran (Nofrion, 2017;12-13). Jika ini dibiarkan akan menghambat tercapainya tujuan pembelajaran.

Selain aktivitas belajardan soal-soal yang berkualitas, keberhasilan dalam proses pembelajaran didukung oleh berbagai faktor, salah satunya adalah sumber belajar. Sumber belajar dapat berupa buku teks, bahan ajar, lembar kerja siswa, modul, internet, orang, lingkungan, dan lainnya yang dapat memfasilitasi kegiatan pembelajaran. Dari sumber belajar yang disebutkan, modul merupakan sumber belajar cetak yang banyak digunakan. Modul menurut Prastowo (2013) merupakan salah satu dari jenis bahan ajar, yaitu bahan ajar cetak (printed).

Modul adalah sejumlah bahan yang disiapkan dalam kertas, yang dapat berfungsi untuk keperluan pembelajaran atau penyampaian informasi (Prastowo, 2013). Modul merupakan salah satu sumber belajar yang disusun secara utuh dan sistematis, didalamnya terdiri dari seperangkat pengalaman belajar yang terencana dan didesain untuk membantu peserta didik menguasai tujuan belajar (Turrahima dkk, 2018).

Keuntungan penggunaan modul adalah peserta didik dapat belajar secara mandiri tanpa bantuan guru. Peserta didik mendapatkan kesempatan untuk mencapai hasil belajar maksimal dengan menguasai bahan pelajaran secara tuntas. Peserta didik diperbolehkan mencari sumber belajar dari mana saja, akan tetapi untuk menyeragamkan pokok bahasan yang sesuai dengan silabus, diperlukan bantuan guru untuk menyusun bahan pelajaran. Modul yang disusun dengan cermat sesuai urutan silabus yang digunakan, membantu peserta didik dalam menentukan referensi yang jelas dalam pembelajaran. 
Seiring dengan kemajuan ilmu pengetahuan dan teknologi, aktivitas pembelajaran di sekolah sangat terbantu dengan adanya komputer, laptop, android, dan lain sebagainya. Dan dengan tersedianya jaringan wifi di lingkungan sekolah memudahkan guru dan peserta didik untuk mengakses internet. Dengan memanfaatkan teknologi tersebut, modul bisa dirancang sebagus dan semenarik mungkin dengan aplikasi yang tersedia. Berbagai macam media grafis dapat menguatkan penjelasan materi di dalam modul. Kemudian ditambah dengan menerapkan suatu model pembelajaran di dalam modul, yaitu model POE (Predict, Observe, Explain) agar peserta didik dapat diarahkan sesuai tahap-tahap model tersebut.

POE (Predict, Observe, Explain) (Kearney et al, 2001) adalah model pembelajaran yang bertujuan untuk mengungkap dan menggali kemampuan siswa dalam melakukan prediksi secara individual. (Warsono, 2016). POE (Predict, Observe, Explain) merupakan rangkaian proses pemecahan masalah yang dilakukan oleh siswa melalui tahap prediksi atau membuat dugaan awal, pengamatan atau pembuktian, dan penjelasan terhadap hasil pengamatan. Ketiga tugas siswa dalam model pembelajaran POE yaitu: (1) Predict: pada tahap ini, mintalah peserta didik untk mengamati apa yang akan anda demonstrasikan. Mintalah mereka mengamati fenomena yang didemonstrasikan, kemudian mereka memprediksi hasilnya dan mempertimbangkan hasil prediksinya. (2) Observe: pada tahap ini, guru melaksanakan kegiatan, menunjukkan proses atau demonstrasi dan mintalah peserta didik untuk mencatat apa yang terjadi. (3) Explain: pada tahap ini, guru meminta peserta didik untuk mengajukan hipotesis mengenai mengapa terjadi seperti yang mereka lakukan dan menjelaskan perbedaan antara prediksi yang dibuatnya dengan hasil observasi. (Widyaningrum, 2014; Kearney et al, 2001))

Berdasarkan hasil wawancara dengan guru mata pelajaran geografi di SMA Negeri 1 Bukittinggi, bahwa bahan pelajaran yang disusun oleh guru masih dimuat oleh tulisan-tulisan dan sedikit terdapat media grafisnya. Peserta didik merasa cepat bosan jika disuguhi dengan bahan yang hanya memuat tulisan dan sedikit terdapat media grafisnya. Peserta didik menjadi kurang berminat membaca dan mempelajari bahan yang sudah ada tersebut.

Menanggapi masalah tersebut, maka perlu suatu tindakan perbaikan pada proses pembelajaran, agar tujuan pembelajaran dapat dicapai dengan maksimal. Salah satu alternatif yang dapat membuat siswa tertarik untuk membaca dan mempelajari modul adalah merancang dan memperbaharui modul sebagus dan semenarik mungkin. Dan melakukan pengembangan terhadap modul dengan penambahan penerapan model POE (Predict, Observe, Explain), yang nantinya akan membantu dan 
mengarahkan siswa dalam mempelajari modul (Kearney et al, 2001).

Perlunya pengembangan modul, agar ketersediaan modul sesuai dengan kebutuhan siswa, tuntutan kurikulum, dan tuntutan pemecahan masalah belajar. Pengembangan modul harus sesuai dengan kurikulum 2013 yang salah satu karekteristiknya adalah menuntut siswa untuk aktif dan berpikir kritis. Karena itu penulis tertarik melakukan penelitian dengan judul "Pengembangan Modul Geografi Berbasis POE (Predict, Observe, Explain) pada materi Pemanfaatan Peta, Penginderaan Jauh, dan SIG di Kelas XII SMA Negeri 1 Bukittinggi”.

\section{METODE PENELITIAN}

Jenis penelitian yang digunakan adalah penelitian dan pengembangan atau Research and Development (R\&D). Penelitian ini dilakukan dengan 4 tahapan pengembangan atau 4-D, yaitu tahap define (pendefinisian), tahap design (perancangan), develop (pengembangan), dan disseminate (penyebaran).

Penelitian ini dilakukan di SMA Negeri 1 Bukittinggi pada bulan Desember tahun pelajaran 2017/2018. Subjek penelitian ini adalah guru geografi dan siswa kelas XII IPS 1 SMA 1 Bukittinggi. Objek penelitian ini adalah modul geografi berbasis POE (Predict, Observe, Explain) pada materi pemanfaatan peta, penginderaan jauh, dan SIG Kelas XII SMA.
Instrumen pengumpulan data penelitian ini ada dua jenis, yaitu angket uji validitas dan praktikalitas modul berbasis POE (Predict, Observe, Explain) pada materi pemanfaatan peta, penginderaan jauh, dan SIG. Untuk menguji kevalidan dan kepraktisan modul geografi berbasis POE pada materi pemanfaatan peta, penginderaan jauh dan SIG, dilakukan uji validitas dan uji praktikalitas terhadap modul.

Analisis validitas menggunakan skala likert yang dimodifikasi dari Riduwan (2012); Audina dkk, (2018), dengan alternatif jawaban, yaitu $1=$ sangat tidak sesuai, 2 = tidak sesuai, $3=$ cukup sesuai, $4=$ sesuai, $5=$ sangat sesuai

Analisis validitas modul berdasarkan lembar validasi dilakukan dengan langkah-langkah berikut.

1. Memberi skor untuk setiap item jawaban, sangat sesuai $=5$, sesuai $=4$, cukup sesuai $=3$, tidak sesuai $=2$, dan sangat tidak sesuai $=1$.

2. Menentukan skor tertinggi $=$ jumlah validator $\mathrm{x}$ jumlah indikator $\mathrm{x}$ skor maksimum

3. Menentukan jumlah skor dari masingmasing validator dengan menjumlahkan semua skor yang diperoleh dari masing-masing indikator

4. Penentuan validitas dengan cara:

$$
\mathrm{R}=\frac{\sum_{j}^{n}=v_{i j}}{n m}
$$

5. Keterangan:

$\mathrm{R}=$ rata-rata hasil penilaian para ahli 
$V_{i j=}$ skor hasil penilaian para ahli

ke $\mathrm{j}$ terhadap kriteria i

$\mathrm{n}=$ banyak para ahli yang menilai

$\mathrm{m}=$ banyak criteria

6. Memberikan penilaian validitas sesuai kriteria pada table 1 di bawah ini.

Tabel 1. Kategori Validitas Modul Geografi Berbasis POE (Predict, Observe, Explain).

\begin{tabular}{ccc}
\hline No & Nilai & Kriteria \\
\hline 1 & $0,75-0,95$ & sangat valid \\
2 & $0,54-0,74$ & Valid \\
3 & $0,33-0,53$ & cukup valid \\
4 & $0,12-0,32$ & kurang valid \\
5 & $<0,12$ & tidak valid \\
\hline
\end{tabular}

Sumber: Modifikasi (Winda, 2010).

Suatu produk dikatakan praktis jika siswa dapat menggunakan modul berbasis POE dalam pembelajaran secara efektif dan efisien. Kepraktisan produk dianalisis berdasarkan angket yang telah diisi oleh guru dan siswa. Analisis validitas menggunakan skala likert yang dimodifikasi dari Riduwan (2012: 81), dengan alternatif jawaban, yaitu $1=$ sangat tidak sesuai, 2 = tidak sesuai, $3=$ cukup sesuai, $4=$ sesuai, $5=$ sangat sesuai.

Analisis data angket praktikalitas menggunakan rumus: $\quad \mathrm{X}=\frac{\sum \mathrm{x}}{N}$ Keterangan:

$\overline{\mathrm{X}}=$ nilai rata-rata responden

$\sum \mathrm{X}=$ jumlah nilai seluruh responden $\mathrm{N}=$ jumlah responden
Setelah nilai kepraktisan diperoleh, dilakukan pengelompokan sesuai kriteria pada table 2 di bawah ini.

Tabel 2. Kategori Praktikalitas Modul Geografi Berbasis POE (Predict, Observe, Explain).

\begin{tabular}{ccc}
\hline No & Nilai & Kriteria \\
\hline 1 & $4,45-4,50$ & sangat praktis \\
2 & $3,39-4,44$ & Praktis \\
3 & $2,33-3,38$ & cukup praktis \\
4 & $1,27-2,32$ & kurang praktis \\
5 & $<1,27$ & tidak praktis \\
\hline
\end{tabular}

Sumber: Modifikasi (Winda, 2010).

\section{HASIL DAN PEMBAHASAN}

\section{A. Pengembangan Modul Geografi Berbasis POE (Predict, Observe, Explain) pada Materi Pemanfaatan Peta, Penginderaan Jauh, dan SIG}

Proses pengembangan modul geografi berbasis POE (Predict, Observe, Explain) pada materi pemanfaatan peta, penginderaan jauh, dan SIG ini terdiri dari 4 tahap pengembangan, yaitu:

\section{Tahap Define (Pendefinisian)}

Tahap pendefinisian teriri dari 3 langkah analisis, yaitu analisis awalakhir, analisis siswa, dan analisis materi.

\section{a. Analisis Awal-Akhir}

Berdasarkan hasil penelitian diperoleh gambaran bahwa guru masih terkendala dalam menyediakan modul yang dapat menarik minat siswa untuk membaca dan mempelajarinya. Modul yang digunakan guru masih dimuat oleh 
tulisan-tulisan dan sedikit terdapat media grafisnya. Oleh karena itu dilakukan pengembangan terhadap modul yang berbasis POE (Predict, Observe, Explain), agar ketersediaan modul sesuai dengan kebutuhan siswa.

\section{b. Analisis Siswa}

Analisis siswa dilakukan untuk mengetahui bagaimana karakteristik siswa SMAN 1 Bukittinggi. Dari analisis yang dilakukan didapat beberapa karakteristik siswa yaitu: (1) Khusus di kelas penelitian yaitu XII IPS 1 berjumlah 35 orang siswa, terdiri dari 12 orang lakilaki dan 23 orang perempuan, (2) dari materi pembelajaran kelas XII, materi pemanfaatan peta, penginderaan jauh, dan SIG tergolong sulit bagi siswa, karena materi ini perlu pemahaman mendalam mengenai peta, penginderaan jauh, dan SIG terlebih dahulu, baru kemudian dianalisis pemanfaatannya, (3) minat baca dan perhatian siswa masih kurang terhadap pembelajaran geografi, disebabkan siswa cepat merasa bosan dengan bahan pelajaran yang hanya memuat tulisan dan sedikit terdapat media grafisnya, (4) siswa bersifat sangat terbuka dengan perkembangan ilmu pengetahuan dan teknologi.

\section{c. Analisis Materi}

Dalam pelaksanaan pembelajaran, SMA Negeri 1 Bukittinggi melaksanakan kurikulum 2013 yang mengacu pada Permendikbud nomor 21 tahun 2016 tentang standar isi yang memuat tentang tingkat kompetensi dasar dan kompetensi inti sesuai dengan jenjang dan jenis pendidikan tertentu. Kompetensi inti meliputi sikap spiritual, sikap sosial, pengetahuan dan keterampilan. Ruang lingkup materi yang spesifik untuk semua mata pelajaran dirumuskan berdasarkan tingkat kompentensi dan kompetensi inti untuk mencapai kompetensi lulusan minimal pada jenjang dan jenis pendidikan tertentu.

Kompetensi dasar pada materi pemanfaatan peta, penignderaan jauh, dan SIG yaitu (3.3) menganalisis jaringan transportasi dan tata guna lahan dengan peta dan atau citra penginderaan jauh serta Sistem Informasi Geografis (SIG) kaitannya dengan pengembangan potensi wilayah dan kesehatan lingkungan, (4.3) menyajikan peta tematik berdasarkan pengolahan citra penginderaan jauh dan Sistem Informasi Geografis (SIG) untuk pengembangan potensi wilayah dan kesehatan.

\section{Tahap Design (Perancangan)}

Tahap design terdiri dari penyusunan materi dan perancangan awal, seperti penjelasan di bawah ini.

\section{Penyusunan materi}

Penyusunan materi dilakukan dengan langkah-langkah dibawah ini:

1) Menentukan dan memahami kompetensi inti (KI) dan kompetensi dasar (KD)

2) Merumuskan indicator pencapaian kompetensi

3) Mencari referensi untuk pembuatan modul 
4) Mencari gambar yang terkait dengan materi pemanfaatan peta, penginderaan jauh, dan SIG

5) Menyusun materi di dalam modul

6) Membuat soal latihan dan tugas untuk siswa sebagai evaluasi pemahaman siswa terhadap materi pemanfaatan peta, penginderaan jauh, dan SIG.

\section{Perancangan awal}

Perancangan awal dilakukan dengan menentukan buku sumber, menentukan software atau aplikasi pengembangan, dan merancang modul sesuai langkahlangkah di bawah ini.

a) Membuka aplikasi Microsoft word 2010 dan mulai membuat rancangan cover modul, seperti gambar 1 di bawah ini. b) Membuat materi yang akan disajikan di dalam modul pembelajaran seperti penulisan pendahuluan, kompetensi inti, kompetensi dasar, indikator, dan materi yang akan dibahas.

c) Selanjutnya penambahan item grafis seperti gambar, tabel grafik dan icon yang berfungsi untuk memperjelas materi dan memperindah tampilan modul atau menambah nilai estetika.

d) Selanjutnya memasukkan gambar pendukung sebagai penguat penjelasan materi di dalam modul.

e) Selanjutnya memasukkan info/ berita terkait dan membuat soal latihan sebagai refleksi atau umpan balik bagi siswa mengenai materi yang telah dipelajari.

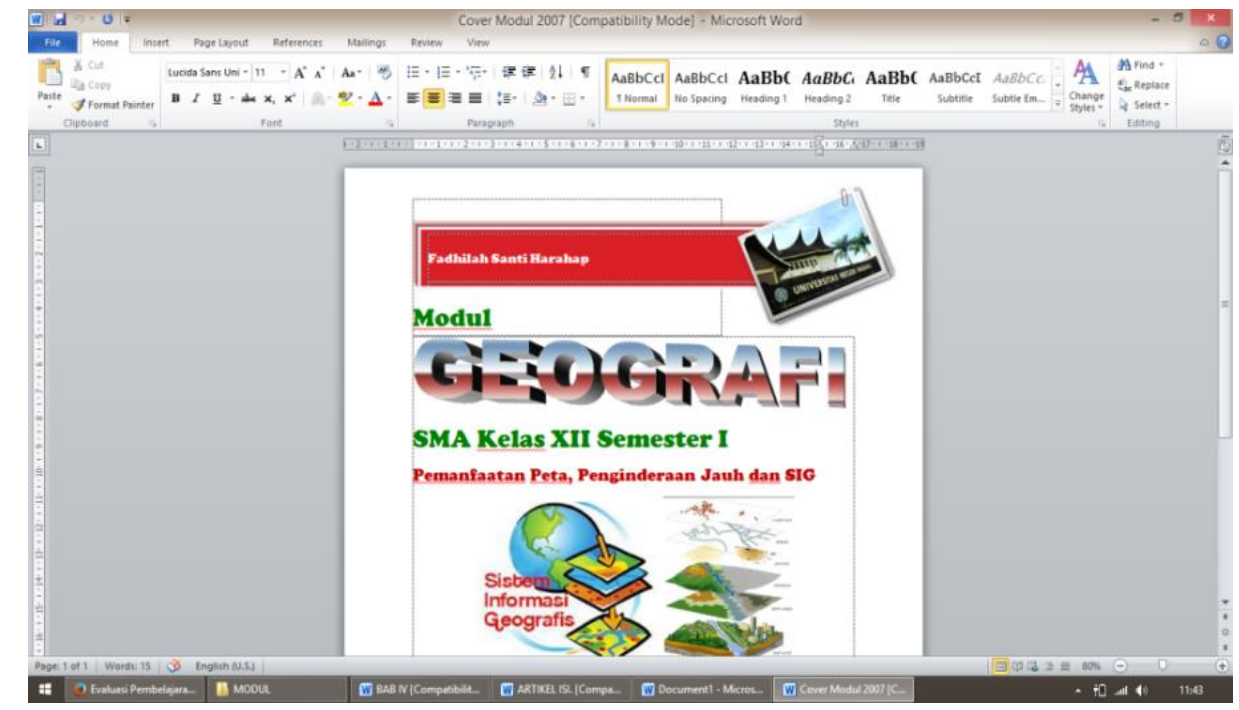

Gambar 1. Tampilan Cover Modul (Dokumensi pribadi, 2017).

\section{Tahap Develop (Pengembangan)}

Tahap pengembangan terdiri dari 4 komponen yaitu: 1) hasil uji kevalidan modul oleh validator, 2) hasil uji kepraktisan modul oleh guru, dan 3) hasil uji kepraktisan modul oleh siswa. 
B. Kevalidan Modul Geografi Berbasis POE (Predict, Observe, Explain) pada Materi Pemanfaatan Peta, Penginderaan Jauh, dan SIG

Untuk menguji valid atau tidaknya modul geografi berbasis POE (Predict, Observe, Explain) dilakukan uji validitas yang terdiri dari 4 aspek penilaian, yaitu aspek kelayakan materi, aspek kebahasaan, aspek penyajian materi, dan aspek kegrafisan. Kevalidan modul geografi berbasis POE (Predict, Observe, Explain) dapat dilihat dalam tabel 3 di bawah ini.

Tabel 3. Hasil Uji Validitas Modul Geografi Berbasis POE (Predict, Observe, Explain).

\begin{tabular}{clc}
\hline No & Aspek yang dinilai & Nilai \\
\hline 1 & Kelayakan materi & 0,59 \\
2 & Kebahasaan & 0,95 \\
3 & Penyajian materi & 0,59 \\
4 & Kegrafisan & 0,69 \\
\hline
\end{tabular}

Total akhir/ Kategori $\quad 0,70 /$ valid

Sumber: Data Primer 2017.

Berdasarkan tabel 7 dapat diketahui bahwa modul geografi berbasis POE (Predict, Observe, Explain) pada materi pemanfaatan peta, penginderaan jauh dan SIG berada pada kategori valid dengan nilai akhir 0,70 .

\section{Kepraktisan Modul Geografi Berbasis POE (Predict, Observe, Explain) pada Materi Pemanfaatan Peta, Penginderaan Jauh dan SIG}

Untuk menguji praktis atau tidaknya modul geografi berbasis POE (Predict, Observe, Explain) dilakukan uji kepraktisan terhadap guru dan siswa yang terdiri dari 3 aspek penilaian, yaitu aspek kemudahan penggunaan dan tampilan, aspek efisiensi waktu pembelajaran, dan aspek manfaat. Kepraktisan modul geografi berbasis POE (Predict, Observe, Explain) yang telah dilakukan terhadap guru dan siswa dapat dilihat dalam tabel 4 dan 5 di bawah ini.

Tabel 4. Hasil Uji Kepraktisan Modul geografi berbasis POE (Predict, Observe, Explain) terhadap Guru

\begin{tabular}{clc}
\hline No & Aspek yang dinilai & Nilai \\
\hline 1 & $\begin{array}{l}\text { Kemudahan } \\
\text { penggunaan dan } \\
\text { tampilan }\end{array}$ & 4,47 \\
2 & $\begin{array}{l}\text { Efisiensi waktu } \\
\text { pembelajaran }\end{array}$ & 4,00 \\
3 & Manfaat & 4,16 \\
\hline Total akhir/ kategori & $\begin{array}{c}\mathbf{4 , 2 1 /} \\
\text { praktis }\end{array}$ \\
\hline
\end{tabular}

Sumber: Data Primer, 2017.

Tabel 5. Hasil Uji Kepraktisan Modul geografi berbasis POE (Predict, Observe, Explain) terhadap Siswa.

\begin{tabular}{clc}
\hline No & Aspek yang dinilai & Nilai \\
\hline 1 & $\begin{array}{l}\text { Kemudahan } \\
\text { penggunaan }\end{array}$ & 4,45 \\
2 & $\begin{array}{l}\text { Efisiensi waktu } \\
\text { pembelajaran }\end{array}$ & 4,14 \\
3 & Manfaat & 4,50 \\
\hline Total akhir/ kategori & $\begin{array}{c}\mathbf{4 , 3 6 /} \\
\text { praktis }\end{array}$ \\
\hline
\end{tabular}

Sumber: Data Primer, 2017.

Berdasarkan tabel 4 dan 5 dapat diketahui bahwa modul geografi berbasis POE (Predict, Observe, Explain) pada materi pemanfaatan peta, penginderaan 
jauh dan SIG yang diujikan kepada guru berada pada kategori praktis dengan nilai akhir 4,21. Tabel 9 juga menunjukkan modul geografi berbasis POE (Predict, Observe, Explain) pada materi pemanfaatan peta, penginderaan jauh dan SIG yang diujikan kepada siswa berada pada kategori praktis dengan nilai akhir 4,36 .

\section{PENUTUP}

\section{Kesimpulan}

Berdasarkan hasil penelitian pengembangan modul geografi berbasis POE (Predict, Observe, Explain) pada materi pemanfaatan peta, penginderaan jauh dan SIG di kelas XII SMA Negeri 1 Bukittinggi, dapat disimpulkan bahwa:

1. Pengembangan modul geografi berbasis POE (Predict, Observe, Explain) pada materi pemanfaatan peta, penginderaan jauh dan SIG dilakukan dengan empat tahap prosedur pengembangan yaitu model 4- $D$ yang terdiri dari 4 tahap: tahap pendefinisian (define), tahap perancangan (design), tahap pengembangan (develop), dan tahap penyebaran (disseminate).

2. Tingkat kevalidan modul geografi berbasis POE (Predict, Observe, Explain) pada materi pemanfaatan peta, penginderaan jauh dan SIG diketahui dari uji validitas modul yang dilakukan oleh validator. Penilaian validitas modul mendapatkan nilai akhir 0,70 dengan kategori "valid".
3. Tingkat kepraktisan modul geografi berbasis POE (Predict, Observe, Explain) pada materi pemanfaatan peta, penginderaan jauh dan SIG diketahui dari uji kepraktisan modul yang dilakukan oleh guru dan siswa. Penilaian kepraktisan modul dari guru mendapatkan nilai akhir 4,21 dengan kategori "praktis", dan penilaian kepraktisan modul dari siswa mendapatkan nilai akhir 4,36 dengan kategori "praktis".

\section{Saran}

Berdasarkan penelitian dan pengembangan modul geografi berbasis POE materi pemanfaatan peta, penginderaan jauh, dan SIG, penelitian ini masih memiliki banyak kelemahan. Oleh karena itu beberapa saran pemanfaatan dan pengembangan modul lebih lanjut yang dibutuhkan adalah:

1. Pada penelitian sejenis disarankan melakukan penelitian sampai tahap efektifitas sehingga memperoleh hasil yang lebih maksimal

2. Guru dapat menggunakan modul berbasis POE ini sebagai salah satu bentuk variasi dari modul yang telah digunakan dalam proses pembelajaran geografi di sekolah.

3. Siswa dapat menggunakan modul berabasis POE ini untuk menambah pemahaman terhadap materi pembelajaran geografi.

\section{DAFTAR PUSTAKA}


Audina, N., Suasti, Y dan Chandra, D. 2018. PERILAKU MASYARAKAT TERHADAP HUTAN NAGARI, NAGARI PAKAN RABAA KECAMATAN KOTO PARIK GADANG DIATEH KABUPATEN SOLOK SELATAN. JURNAL BUANA, 1(1), 82-82.

Daryanto. 2013. Pengembangan Perangkat Pembelajaran. Yogyakarta: Gava Media.

Kearney, M., Treagust, D. F., Yeo, S and Zadnik, M. G. 2001. Student and teacher perceptions of the use of multimedia supported predictobserve-explain tasks to probe understanding. Research in Science Education, 31(4), 589615.

Nofrion, N. 2018. Effectiveness of EXO OLO TASK Learning Model Based on Lesson Study in Geography Learning. IOP Conf. Series: Earth and Environmental Science 145 (2018) 012038 doi :10.1088/1755$1315 / 145 / 1 / 012038$

Nofrion. 2017. Peningkatan Aktivitas Belajar Siswa Melalui Penerapan Metode Jumping Task pada Pembelajaran Geografi. E_Journal Geografi UNIMED.Volume 9, Nomor 1 tahun 2017. Hal 11-20.

Prastowo, A. 2013. Panduan Kreatif Membuat Bahan Ajar Inovatif. Yogyakarta: Diva Press.
Putra, A. 2010. Penerapan Pembelajaran Kooperatif Model Group Investigation Pada Mata Pelajaran IPS Geografi. Laporan Penelitian Tindakan Kelas. Pusat Program Pengalaman Lapangan, Universitas Negeri Padang.

Suasti, Y. 2003. dkk, Upaya Peningkatan Kreativitas Siswa SMU Pembangunan UNP Melalui Modifikasi Cooperative Learning Model Jigsaw. Padang: Buletin Pembelajaran Universitas Negeri Padang.

Suasti, Y., Barlian, E., Muchtar, Bustari, Syah, N and Putra, A. 2018. Insert Religious Model in the Construction Character of Care for the Environment to the Study of Geography in Padang City Indonesia. Journal of Islamic Studies and Culture, 6(1).

Riduwan. 2012. Skala Pengukuran Variabel-Variabel Penelitian dan Pengembangan. Jakarta: PT Raja Grafindo Persada

Turrahima, N., Suasti, Y dan Nofrion. 2018.. ANALISIS AKTIVITAS BELAJAR SISWA DALAM PEMBELAJARAN GEOGRAFI DI KELAS $X$ IIS 1 SMA NEGERI 4 PADANG. Journal of GEOGRAPHY, 5(2), 169-169.

Warsono. 2016. Model-Model Pembelajaran Inovatif. Bandung: Yrama Widya

Widyaningrum. 2014. Metode dan Model Pembelajaran Inovatif. Jakarta: Bumi Aksara 
Winda. 2010. Pengembangan Bahan Ajar larutan Penyangga dalam Bentuk Modul Berbasis Pendekatan Saintifik untuk Kelas XI SMA/MA. Padang: Skripsi. 